\title{
Graft Copolymerization of Acrylonitrile and Ethyl Methacrylate on Dextrin
}

\author{
F. E. Okieimen, R. O. Amaye and A. Jideonwo* \\ Department of Chemistry, University of Benin, Benin City.
}

\begin{abstract}
Graft copolymers of Acrylonitrile and ethyl methcrylate on dextrin were prepared by the use of ceric ion initiator in aqueous medium at $29^{\circ} \mathrm{C}$. The molecular weight of grafted poly(ethyl methacrylate) chains were higher than for polyacrylonitrile grafts; but the latter were more frequently grafted on the backbone polymer. The dependence of the molecular weight of the grafted chains on ceric ion concentration suggests that interaction of growing graft polymer chains with ceric ion is important in the termination process of graft copolymerisation. Graft copolymeriation of ethyl methacrylate onto dextrin in the presence of various amounts of acrylonitrile was studied. The compositions of the copolymer samples, calculated from their nitrogen content, showed that in the presence of ethyl acrylate, relatively small amounts of acrylonitrile monomer was grafted onto dextrin.
\end{abstract}

\section{INTRODUCTION}

Ceric ion has been used to initiate graft copolymerisation of many monomers on various substrates ${ }^{1-7}$. Grafting is generally considered to result from propagation by radicals generated on the backbone polymer. It is well accepted that the extent of graft polymer formation depends on the nature and reactivity of the backbone polymer towards initiation of graft polymer formation, the reactivity of the active sites towards propagation, the nature of termination reactions of copolymerisation, and the polarity of the monomer. Several workers have reported on graft copolymerisation onto $\operatorname{starch}^{8-10}$. Graft copolymers of polysaccharides are of interest ${ }^{11}$. This communication examines some aspects of graft copolymerisation onto dextrin.

\section{EXPERIMENTAL}

Acrylonitrile (AN) and ethyl methacrylate (EMA) monomers were purified from hydroquinone stabiliser by

* Author for correspondence extraction with aqueous alkaline solution followed by distillation. Ceric ammonium nitrate was used without further purification. Dextrin was used without further purification. Dextrin was prepared from cassava starch using $20 \%$ $(\mathrm{v} / \mathrm{v})$ hydrochloric $\operatorname{acid}^{12}$. Cassava starch $(20.0 \mathrm{~g})$ was moistened with $5 \mathrm{ml}$ of dilute aqueous hydrochloric acid (0.2 vol. \%), spread on a tray and heated at $60^{\circ} \mathrm{C}$ for $2 \mathrm{hr}$ in an oven. The acidified starch was further heated at $100^{\circ} \mathrm{C}$ for $5 \mathrm{hrs}$ and $100^{\circ} \mathrm{C}$ for another $5 \mathrm{hrs}$; and cooled in a dessicator. Graft copolymerisation was based on the method described by Lepoutre and $\mathrm{Hui}^{13}$ for grafting onto woodpulp.

A known amount of dextrin $(0.5 \mathrm{~g})$ was dissolved in $100 \mathrm{ml}$ of deionised water containing a definite amount of ceric ion. The initiator was allowed to interact with dextrin for 30 mins and then a definite amount of the monomer was added dropwise. The polymerisation was allowed to proceed for $4 \mathrm{hrs}$ and then stopped by the addition of $5 \mathrm{ml}$ of $2 \%$ $(\mathrm{v} / \mathrm{v})$ wuinol solution to the reaction mixture. The reaction mixture was poured into an excess of methanol and filtered. The residue was air-dried and weighed. The ungrafted poly(ethyl 
methacrylate) (PEMA) and polyacrylonitrile (PAN) homopolymers were extracted with benzene and dimethyl formamide respectively. The

dextrin graft copolymer was air-dried and weighed. The percentage graft level, $(\mathrm{Pg})$, was calculated from the weights of dextrin and grafting products.

$$
\operatorname{Pg}=\quad \frac{\text { weight of grafted polymer } \times 100}{\text { Weight of dextrin }}
$$

Graft copolymerization of ethylacrylate $(0.24 \mathrm{~m})$ in the presence of various amounts of acrylonitrile using $0.2 \mathrm{M}$ ceric ion was also studied $29^{\circ} \mathrm{C}$.

The grafted PEMA and PAN chains were isolated from the backbone polymer by treatment with hydrochloric acid $^{8}$. The isolated PEMA and PAN grafts were purified by solution in benzene and dimethylformamide respectively and precipitation with methanol and airdried. The molecular weights of the polymers were determined from viscosity measurement using the following relationships

$\log (\mathrm{y})=\log 4.75 \times 10^{-4}+0.50 \mathrm{Mv}$

$\log (\mathrm{y})=\log 3.35 \times 10^{-4}+0.72 \mathrm{Mv}$

for PEMA in isopropanol at $30^{\circ} \mathrm{C}$ and PAN in dimethylformamide at $30^{\circ} \mathrm{C}$ respectively. The frequency of grafting (FG), defined as the number of polymer grafts per $10^{4}$ anhydroglucose units (AGU), was calculated using the relationships

$$
\mathrm{Fg}=\frac{\text { (weight of grafted polymer })(\mathrm{mw} \text { of AGU)*104 }}{\text { mw of grafted polymer }}
$$

The nitrogen content of the grafted PEMA-PAN copolymer samples was determined by the Kjedahl method. The copolymer compositions were worked out from the nitrogen content of the samples using the relationship

$$
\underset{\mathrm{AN} \text { in copolymer }}{\text { mole fraction of }}=\frac{(\mathrm{BxN}) / 14 \mathrm{~B}^{-1}}{1-(\mathrm{BxN}) / 14 \mathrm{C}^{-1}+(\mathrm{BxN}) / 14 \mathrm{~B}^{-1}}
$$

Here $\mathrm{N}$ is the weight of nitrogen per gram of copolymer sample, $\mathrm{B}$ is the molecular weight of acrylonitrile and $\mathrm{C}$ is the molecular weight of ethyl methacrylate.

\section{RESULTS AND DISCUSSION}

The variation of $\mathrm{Pg}$ with ceric ion concentration using $0.16 \mathrm{M}$ EMA and $0.46 \mathrm{M}$ AN is shown in Fig. 1. The results show that the initial increase in $\mathrm{Pg}$ with ceric ion concentration attained maximum values of about $11 \%$ and $225 \%$ for the graft copolymerisation of EMA and AN respectively at $0.2 \mathrm{M}$ ceric ion and decrease with further increase in ceric ion concentration. The low values of $\mathrm{Pg}$ at high initiator concentration have been associated with the formation of ceric ion complex with the backbone polymer ${ }^{14}$ which reduces both the number of grafting sites on the backbone polymer and the amount of ceric ion available to initiate graft polymer formation. The values of $\mathrm{Pg}$ obtained for dextrin are much higher than the values reported for $\operatorname{starch}^{7,15}$. 
Fig 1: Grafting of EMA (o) and AN (i) on dextrin at $29^{\circ} \mathrm{C}$ using $0.16 \mathrm{M}$ EMA and $0.46 \mathrm{M}$ AN Fig 1: Grafting of EMA (o) and AN (i) on dextrin at $29^{\circ} \mathrm{C}$ using $0.16 \mathrm{M}$

EMA and $0.46 \mathrm{M}$ AN

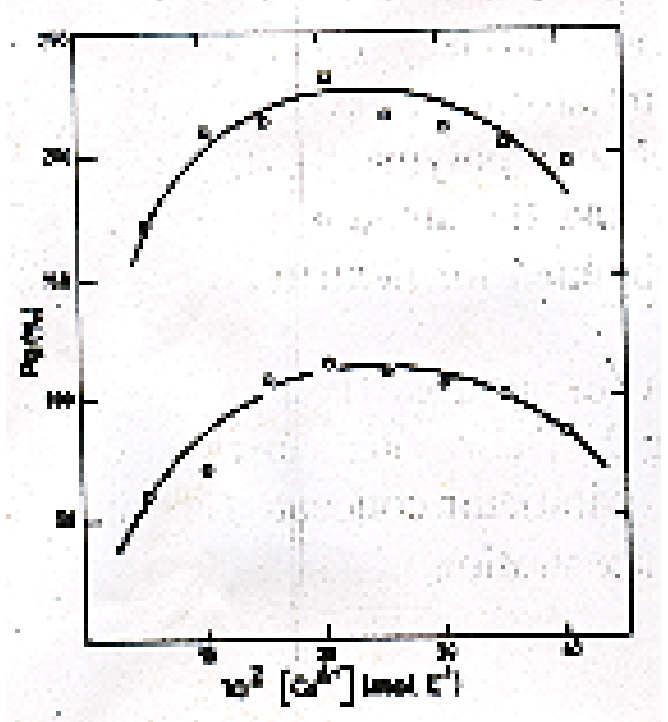

The molecular weights of grafted PEMA and PAN chains at various ceric ion concentrations are shown in Fig. 2. The results show that the molecular weight of grafted PEMA chains increased with increase in initiator concentration up to $0.2 \mathrm{M}$ ceric ion and decreased with further increase in ceric ion concentration.

The molecular weights of grafted PAN chains, on the other hand, decreased with increase in ceric ion concentration. The dependence of the molecular weight of the grafted chains on ceric ion concentration suggests that termination of graft copolymerisation by the interaction of growing graft polymer chains with ceric ion would be the main termination process in the copolymerisation of AN and would become significant at relatively high ceric ion concentration. It is well recognized that in such polymerisation, where mutual termination of growing polymer chains are low, the chain transfer constant $\left(\mathrm{K}_{\mathrm{A}} / \mathrm{K}_{\mathrm{P}}\right)$, can be determined from the plot of ${ }^{1} / \mathrm{N}$ against ceric ion concentration using the relationship

$$
1 / \mathrm{N}=1 / \mathrm{N}_{\mathrm{o}}+\mathrm{K}_{\mathrm{A}}\left[\mathrm{Ce}^{4+}\right] / \mathrm{K}^{\mathrm{p}}[\mathrm{M}]
$$

Fig 2: Dependence of the Moleular weight grafted PEMA (o) and PAN (i) chains on ceric ion concentration

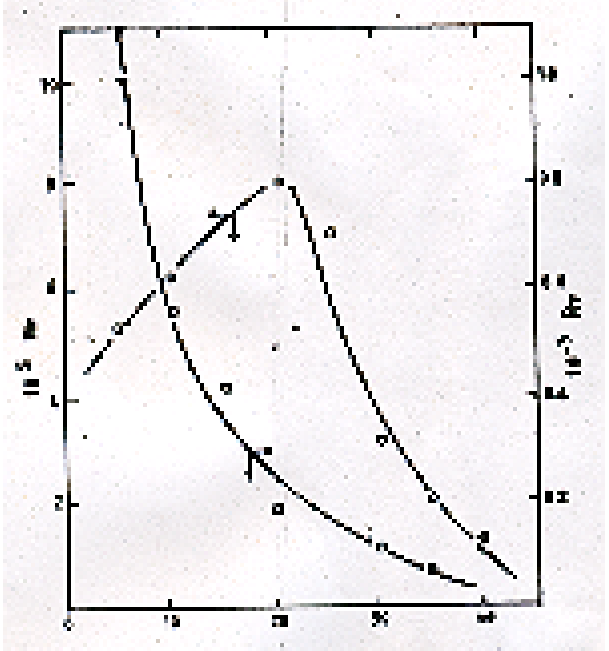

Here $\mathrm{N}$ and No are the degrees of graft copolymerisation in the presence and absence of ceric ion respectively.

It can be seen from the plots in Fig. 3 that termination of copolymerisation chain transfer to ceric ion is important at high initiator concentrations. The values of the transfer constant were determined to be $3.68 \times 10^{-5}$ and $3.30 \times 10^{-4}$ for the graft copolymerisation of EMA and AN respectively.

Fig 3: Chain transfer to ceric ion in the graft copolymerization at EMA (o) and AN (i) on dextrin at $29^{\circ} \mathrm{C}$

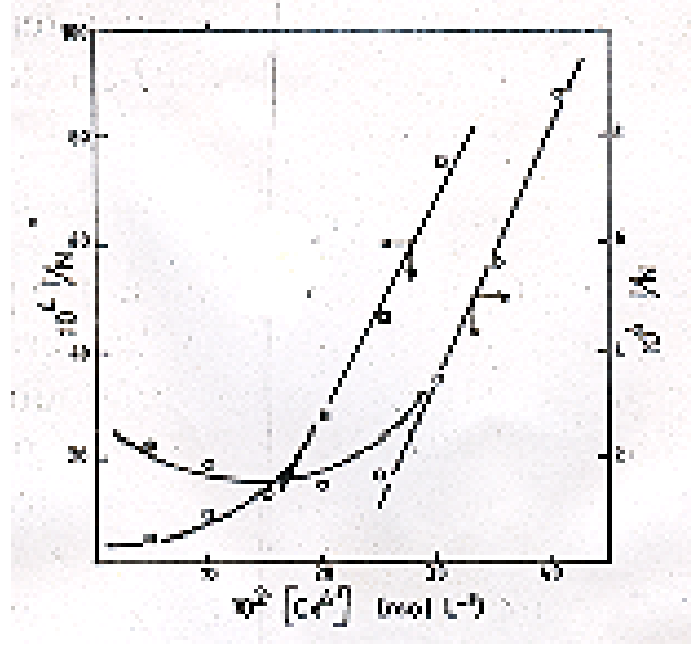


$\mathrm{Li}$ and $\mathrm{Fu}^{16}$ in their study of the graft copolymerisation of butyl acrylate on gelatin proposed relationships between the rate of graft copolymerisation (RG) and ceric ion concentration for cases where termination occurs by the interaction of two growing graft polymer chains as

$\mathrm{Rg}=\left(\mathrm{k}_{\mathrm{p}} \mathrm{k}_{\mathrm{d}} / \mathrm{kt}_{1}\right)\left\{\mathrm{k}[\mathrm{Dex}]\left[\mathrm{Ce}^{4+}\right]^{1 / 2}\right\} / \mathrm{kdk}[\mathrm{Dex}]+\mathrm{k}_{1}[\mathrm{M}]^{1 / 2}$

and where termination occurs by the interaction of ceric ion with growing graft polymer chains.

$\left.\mathrm{Rg}=\left(\mathrm{k}_{\mathrm{p}} \mathrm{k}_{\mathrm{d}} / \mathrm{k}\right) / \mathrm{kt}_{2}\{\mathrm{M}\}^{2}[\mathrm{Dex}]\right\} /[\mathrm{M}]+\left\{\mathrm{k}_{0} / \mathrm{k}_{1}\right)\left\{\mathrm{Ce}^{4+}\right\}$

Equations 7 and 8 predict that the kinetic order of the rate of graft polymerisation in initiator would be 0.5 and -1 for termination of copolymerisation brought about by mutual combination of growing polymer radicals and termination by chain transfer process respectively. The rate of graft copolymerisation can be obtained from the relationship.

$\operatorname{Rg}=$ (weight of grafted polymer) x 1000

(mw of monomer)(reaction time)(reaction volume)

The effect of ceric ion concentration on the rate of graft copolymerisation of EMA and $\mathrm{AN}$ on dextrin is shown in Fig. 4. It can be seen that the plots of $\mathrm{Rg}$ against initiator concentration are linear at low ceric ion concentration, which agrees with mutual termination of growing polymer chains. At higher initiator concentration, the plots deviate from linearity, suggesting that termination of copolymerisation probably is due to transfer to ceric ion. It has been argued that for polymerisation in aqueous dextrin solution, the rates of

Fig 4: Dependence of rate of graft copolymerization of EMA (o) and AN (i) on dextrin at $29^{\circ} \mathrm{C}$

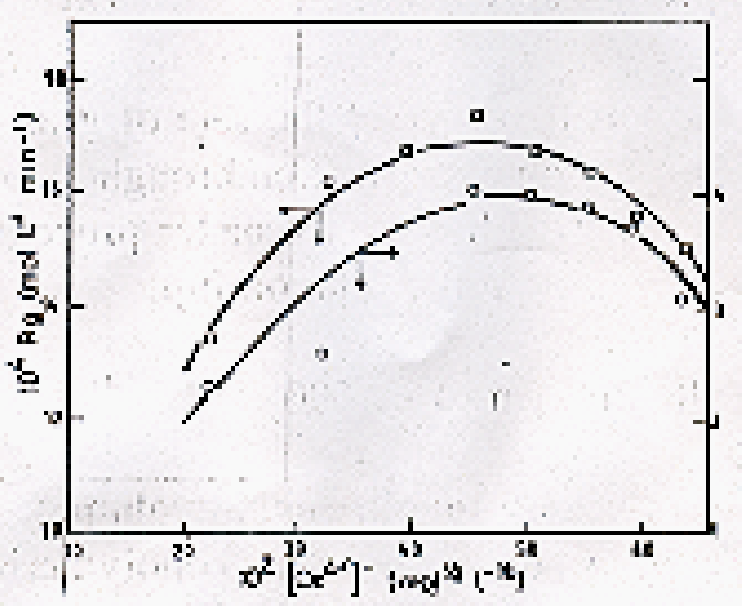

Nigeria Journal of Chemical Research mutual termination of growing graft polymer chains would be low and diffusion controlled. Such would be the case at low conversions of monomers to polymer and termination of graft coplymerization would proceed mainly by transfer reactions (9). Fig 5 shows the variation of $\mathrm{Fg}$ with ceric ion concentration. The number of grafted polymer molecules per $10^{4}$, AGU, varies from about two to eleven and from

Fig 5: Graft copolymerization onto dextrin Dependence of Fg of PEMA(o) and PAN (i) on ceric ion concentration.

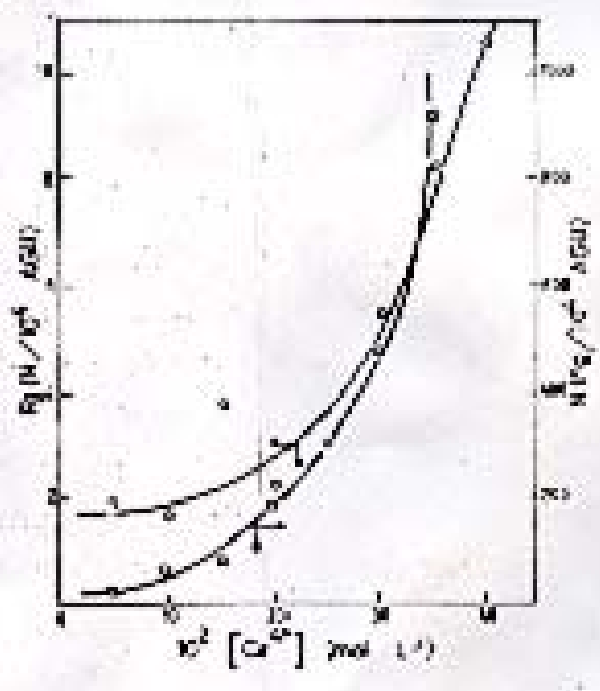

Vol. 11, 2006 
twenty-six to more than nine hundred for the graft copolymerisation of EMA and AN respectively on dextrin. Fanta and Coworkers ${ }^{5}$ in a study of copolymerisation of acrylonitrile on a variety of starch samples reported that graft copolymerisation in dilute aqueous starch dispersion enhanced the frequency of grafting. It is thought that the reactive end groups produced during the dextrinisation process would explain the fairly high frequencies of grafting on dextrin.

The influence of acrylonitrile on the grafting of EMA on dextrin is shown in Fig. 6. The results show that Pg increases with the AN content of the feed composition. The increase in $\mathrm{Pg}$ with increasing proportion of $\mathrm{AN}$ in the monomer mixture suggests that the reactivity of a growing graft copolymer chain is either accentuated by the presence of monomeric units of $\mathrm{AN}$ or that $\mathrm{AN}$ molecules are grafted independently of the EMA molecules.

Fig 6: Grafting EMA on dextrin in the presence of $\mathrm{AN}$ variation of $\mathrm{Pg}$ and nitrogen content of the copolymer with AN content of the Feed using 0.24

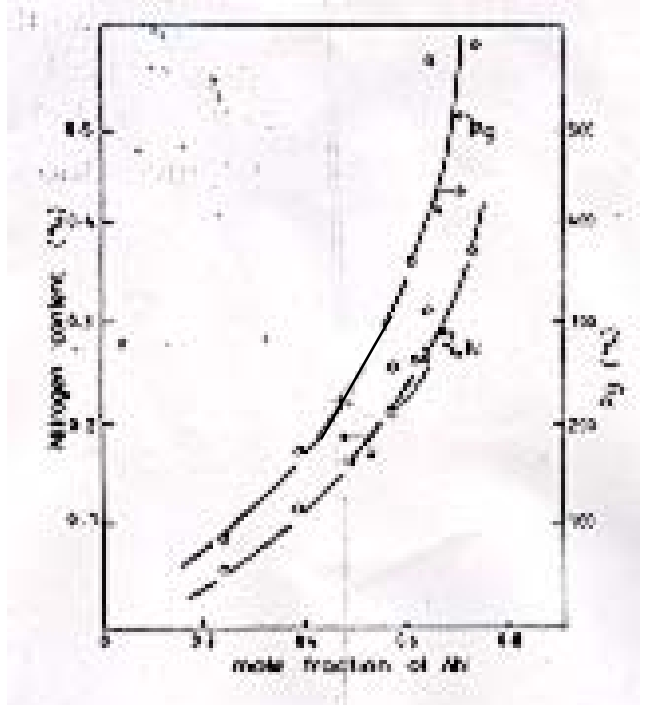

The variation of the nitrogen content of the grafted copolymer with the relative amount of $\mathrm{AN}$ in the monomer mixture is shown also in Fig. 6.
The compositions of the copolymer samples were worked out from their nitrogen contents according to Eq.5. The results show a general increase in the contents of monomer units of $\mathrm{AN}$ in the copolymer with increasing proportion of $\mathrm{AN}$ in the monomer mixture. However, it can be seen that the increase in AN monomeric units in the copolymer does not correspond to the increase of AN in the feed. For instance an increase in the amount of AN in the feed by as much as $40 \mathrm{~mol} \%$ resulted in less than $3 \mathrm{~mol} \%$ increase in the AN content of the copolymer. Acrylonitrile monomeric units can either be built into the graft copolymer chains randomly with EMA monomeric units or into PAN homopolymer chains. Either way, our method of analysis should account reasonably well for AN monomeric units in the grafting products. For example, determination of AN content of PAN homopolymer by analysis for nitrogen gave about $94 \%$ accuracy ${ }^{17}$.

The low values of $\mathrm{AN}$ content of the copolymer samples even at fairly high AN levels in the feed are indicative of the low reactivity of acrylonitrile in copolymerisation reactions with acrylates $^{18,19}$.

\section{REFERENCES}

1. Mino, G. and Kaizerman, S., J. Polym. Sci., 31 (1958) 242.

2. Khetarpal, R. C., Gill, K. D., Imehta I. K. and Misra, B. N., J. Macromol. Sci. Chem. A18 (1982) 445.

3. Graczyk T. and Hornof, V., J. Macromol. Sci. Chem. A25 (1988) 1633.

4. Taghunath, K., Punduranga, K. and Nagarajan, B., Eur. Polym. J. 21 (1985) 195.

5. Fanta, G. F., Burr, R. C., Russel C. R. and Rist, C. E., J. Appl. Polym. Sci. 13 (1969) 133.

6. Sood, D. S., Kishore, J. and Misra, B. N., J. Macromol. Sci. Chem. A22 (1985) 263. 
7. Okieimen, F. E. and Egharevba, F., Eur. Polym. J. 25 (1989) 99.

8. Brockway, C. E., J. Polym. Sci. Part A. 2 (1964) 3733.

9. Okiemen, F. E., Egharevba, F. and Jideonwo, A. Angew. Makromol. Chem. 84 (1991) 1.

10. Cooper, W. and Vaughan, G., J. Polym. Sci. 37 (1959) 241.

11. Pledger Jr. H., Wu, G. S., Young, T. S., Hogen-Esch, T. E. and Butler, G. B., J. Macromol. Sci. Chem. A22 (1991)1297.

12. Radley, J A., Starch and its derivatives Vol. 1, $3^{\text {rd }}$ ed., Chapman and Hall Ltd., London, 1953.

13. Lepoutre, P. and Hui S. H., J. Appl. Polym. Sci.19 (1975) 1257.

14. Okieimen, F. E. and Idehen, K. I., Acta. Polymerica 39 (1988) 324.
15. Bazuaye, A., Okieimen, F. E. and Said, O. B., J. Polym. Sci., Poly. Letts Ed. 27 (1989) 433.

16. Li, Z. and Fu, J., J. Macromol. Sci. Chem. A25 (1988) 1487.

17. Egharevba, F., Graft Copolymerization of ethyl acrylate onto starch. $\mathrm{PhD}$ Thesis, University of Benin, 1990.

18. Joshi, R. M. and Kapur, S. L., J. Sci. Ind. Res. 16B (1957) 379.

19. Ashikari, N. and Nishimura, J. Polym. Sci. 31(1958) 250.

Received: 01/02/2006

Accepted: 30/06/2006 